$|c| c|l| p|s|$

Center for

Higher Education

Policy Studies

\title{
Unravelling tacit knowledge
}

\section{Engagement Strategies of Centres for Excellence in Teaching and Learning}

\section{CHEPS WORKING PAPER 03/2017}

Andrea Kottmann. CHEPS (University of Twente)

a.kottmann@utwente.nl

Series Editor Contact:

Nadine Zeeman, Katharina Lemmens-Krug \& Paul Benneworth

Centre for Higher Education Policy Studies

University of Twente

P.O. Box 217

7500 AE Enschede

The Netherlands

$\mathrm{T}+3153-4893263$

F +31 53-4340392

E n.zeeman@utwente.nl

W www.utwente.nl/cheps 


\section{Table of Contents}

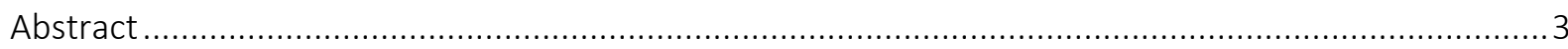

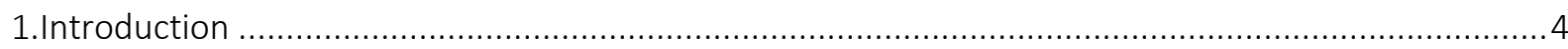

2.CETL and their role in developing a shared understanding of teaching and learning ........................5

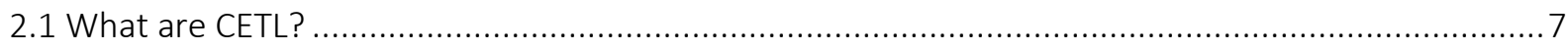

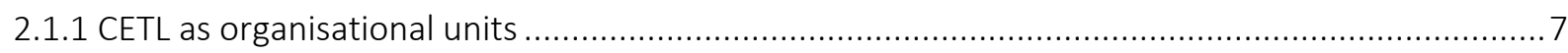

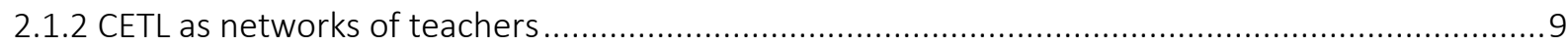

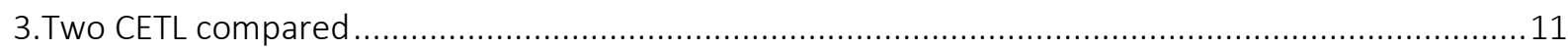

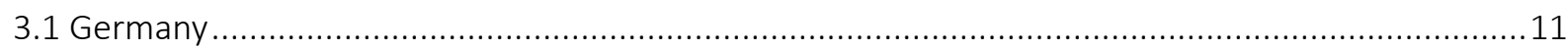

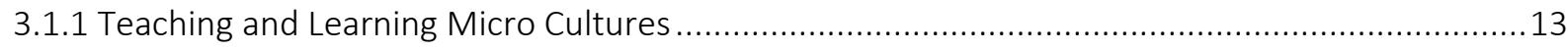

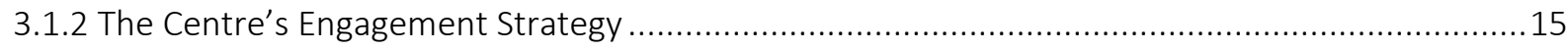

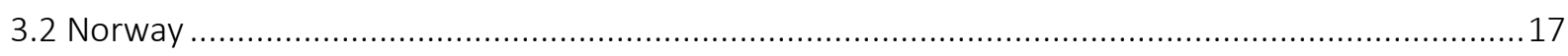

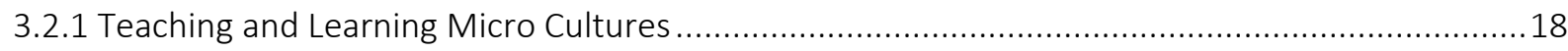

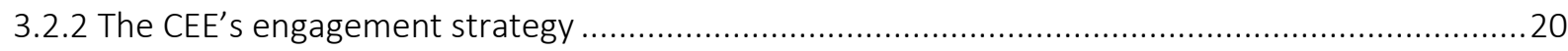

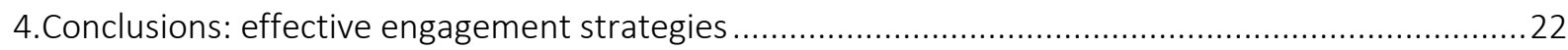

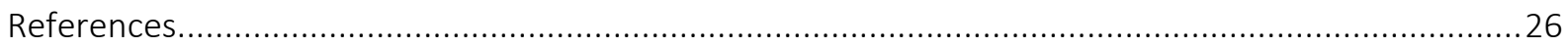




\begin{abstract}
Centres for Excellence in Teaching and Learning or Centres for Teaching and Learning have become widespread across higher education institutions in Europe. These centres can be defined as nodes of "nodes of teaching and learning-focused activities" (Saunders et al. 2008, p. 28). Recent research has shown that centres frequently face difficulties promoting their enhancement activities (Gosling \& Turner, 2014). This is due to a number of reasons, in particular to the low acceptance of the pedagogical knowledge used by the centres among academic staff. It appears that centres often have not developed a strategy to engage academic staff in their enhancement activities. This working paper however investigates the engagement strategies of two Centres for Teaching and Learning, one located at a mono-disciplinary institution in Norway, the other at a research university in Germany. As these centres have been implemented differently, the working paper also discusses how implementation affects the centre's success. As the cases under review are highly contrasting the comparison singles out facilitators and hindrances to effective engagement strategies.
\end{abstract}

Keywords: Centre for Excellence in Teaching and Learning, quality of teaching and learning, enhancement, quality culture 


\section{Introduction}

In the recent years at higher education institutions in Europe the establishment of Centres for Excellence in Teaching and Learning (CETL) has become widespread. Mostly institutions use these centres to implement and coordinate activities improving the quality of teaching and learning, new teaching technologies or to train their teachers. While some institutions establish these centres from their own funds others use national funding schemes such as the Norwegian SFU scheme, the German Quality Pact for Teaching or the (already terminated) CETL scheme by HEFCE.

Research on CETL so far, in particular research done on the HEFCE CETL, stated that CETL have had difficulties to promote activities aiming to improve the quality of teaching and learning. According to (Saunders et al., 2008) this is due to the low acceptance and legitimacy of the pedagogical knowledge generated by CETL among academic staff. Further, due to the lack of an engagement strategy CETL also had difficulties to change teaching practices for a larger group of teachers or to reach out to a wider teaching and learning community (Saunders et al., 2008, p. 5).

This working paper will investigate how engagement strategies of current CETL look like and how they are able to gain more acceptance for pedagogical knowledge. It will argue that developing a shared understanding and shared value for high quality teaching is a key prerequisite to engage teachers in CETL activities and to motivate them to change their teaching practices. Activities aiming to develop shared understandings and values of teaching, however, need to adapt to the teachers' daily practices and help them unravel and reflect their tacit teaching knowledge to be successful. The working paper will further argue that the implementation of a CETL is crucial for the success of its engagement strategy. Therefore, it aims to identify factors and hindrances for developing shared values and a shared understanding of high quality teaching.

To this effect, a CETL in Norway and a CETL in Germany will be compared. The selected cases are highly contrasting. The Norwegian CETL is located a mono-disciplinary and relatively small higher education institution. It is one of the CETL funded by the Norwegian 
SFU programme. The CETL is not an independent department, but has been integrated as a project into the already existing organizational structures of the institution. The German CETL, on the other hand, is an independent service department at the central level of the university funded mainly by its own resources.

The remainder of this working paper is organized as follows: the second section will discuss CETL and the different ways they have been implemented. Further, the section will investigate why shared values and understandings are key to a successful engagement strategy of CETL. The third section will report on to what extent shared value and understandings with regard to teaching and learning have been established among teachers in the two cases under review. Further, the CETL's engagement strategy will be analysed. In the final section the working paper will conclude factors and hindrances to a successful engagement strategy.

\section{CETL and their role in developing a shared understanding of teaching and learning}

Current teaching cultures in higher education can be described as strongly individualized, i.e. teaching often happens as a solitary and private endeavour of the academic. Teachers are often alone in front of class and there is no sharing of teaching tasks, i.e. Teachers are responsible for any task such as developing syllabus, preparing teaching material, doing lectures and assessing students' achievements. The scholarship of teaching and learning, i.e. a methodological and reflective approach to teaching based on learning theories and other didactical knowledge also does not play an important role. More frequently teaching is based on the teachers' experiences such as their own experiences of being taught or on tacit knowledge that has developed in a trial-and-error process throughout their careers. Academic staff hardly exchange about experiences, results and teaching methods with their colleagues. Teachers are also often reluctant to use new methodology or technology in their teaching as they lack sufficient knowledge how to use them. There is often no peer review of teaching activities, also feedback of students provided through evaluations does not 
stimulate a thorough and methodological reflection of teaching activities. Finally, though some teachers take part in initial courses introducing them higher education teaching, but there is often no continuous development or professionalization of teaching competencies.

Current research, however, indicates that a more collaborative teaching culture picking up characteristics of research cultures, such as collaboration, collegiality, continuous development of teaching competencies, peer review, documentation of results and feedback as well as a scholarly approach to teaching would strongly support enhancement activities in teaching and learning. In particular studies done by Mårtensson and Roxå made clear that teachers who have the opportunity to exchange about their teaching practices in social networks are more likely to develop beliefs and ideas about teaching (Mårtensson \& Roxå, 2016b, p. 176). Exchanging with others in significant interactions helps them to develop their teacher identity. A more recent study shows that within these networks micro cultures are established that have some positive impact on teachers' engagement and motivation for teaching as well as for the prestige and status of teaching and learning activities. This is in particular true for networks that strongly support teachers. Teachers involved in significant networks that only provide little support do not engage in teaching and learning activities as strongly, at these institutions teaching and learning has also less prestige/status (Mårtensson \& Roxå, 2016a). The institutional culture or context also impacts on the orientations of teachers. In institutions promoting more learning-oriented approaches academic staff more often engages in these kinds of teaching practices (Mårtensson \& Roxå, 2016b, p. 133). Overall, in their study the authors distinguish between strong and developing micro cultures. Strong micro cultures resemble to some extent Wenger's communities of practices (Wenger, McDermott, \& Snyder): key characteristics are 'strong internal trust, intense interactions, information sharing, and commitment to the group's enterprise, a shared history, and interest in collaboration (Mårtensson \& Roxå, 2016b, p. 136). These strong cultures stimulate a high engagement of teachers for high quality teaching. Developing micro cultures, however, create 'a shared desire to do something new', thus are developing such culture (Mårtensson \& Roxå, 2016b, p. 136). 
In their working paper Mårtensson \& Roxå do not address how networks of teachers have been established and how they are implemented at the institutional level. They focus more on the individual enculturation of teachers and how they develop their teaching identity. This working paper will take a different perspective and investigates how CETL facilitate the communication among teachers to establish strong or developing micro cultures of teaching and learning. It will further argue that the way CETL are established at higher education institutions is crucial to their impact.

\subsection{What are CETL?}

To date the research literature has not yet elaborated a definition of CETL. Research studying the impact of CETL often build on an implicit understanding of CETL as central level departments providing services and activities that seek to promote the enhancement of teaching and learning through the work of education professionals or specialists. This implicit idea is also picked up here. CETL will be understood as "'nodes' of teaching- and learning-focused activities, whose purposes are to enhance quality (and sometimes excellence) in teaching practices and to invest in that practice in order to increase and deepen its impact across a wider teaching and learning community" (Kottmann, Huisman, Brockerhoff, Cremonini, \& Mampaey, 2016; Saunders et al., 2008). CETL, however, have been established very differently at higher education institutions (Challis, Holt, \& Palmer, 2009; Raaheim \& Karjalainen, 2012; SQW, 2011; Webler, 2012). Kottmann \& Cremonini (2017) distinguish between CETL as central organizational units and CETL as networks of teachers at department or faculty level.

\subsubsection{CETL as organisational units}

To facilitate organisational learning some higher education institutions implement CETL as service units that are located at the central administration level. These centres provide services for the whole institution. Mostly these units are assigned to the university leadership, for example to the vice-rector for teaching and learning. The CETL have their own staff who are often educational specialist and do not engage in teaching or research themselves. Their main area of activity is to promote the improvement of teaching and 
learning at their institution. Promotion activities include for example the didactical trainings of academic staff, individual coaching of teachers or coordinating and running teaching development projects. These centres also engage in the dissemination of knowledge of teaching and learning processes by running education days, lecture series, publications on good practices or through websites.

Recent research states that CETL establish a number of collaboration opportunities. Among these were, inter alia enhancing networking and collaboration within the institution as well as outside the institution. They provide staff with the opportunity to try out, develop and study (innovative) teaching methods. They can support the institution in developing a cross-institutional profile in teaching and learning, i.e. shared goals and ideas about high quality teaching. Further, CETL can have an important role in raising the institutional engagement for teaching and learning and thus improve the status of teaching and learning. Finally, CETL often engage in professional training of academic staff, in particular in didactical trainings (Bélanger, Bélisle, \& Bernatchez, 2011; Challis et al., 2009; Gosling \& Turner, 2014; Lieberman, 2005; Raaheim \& Karjalainen, 2012; Saunders et al., 2008; Webler, 2012).

A key feature of these centres is that they take a strong individualized approach to promote the improvement of teaching and learning. There is a strong idea that strengthening the individual competences of teachers will improve the teaching and learning at the institution as a whole. The centres often do not focus on teachers as groups and that developing a more collaborative culture in teaching and learning, i.e. to develop shared understandings of good teaching and learning, could be helpful for engaging teachers in high quality teaching and learning. Rather, it is argued that individual teachers who successfully have run an innovative teaching projects will act as role models and motivate other teachers also to engage in the improvement of their teaching practices.

The literature also defines a number of factors that make CETL successful in stimulating higher education institutions to engage in improving teaching and learning (Gosling \& Turner, 2014; Saunders et al., 2008). Those CETL that are included in the strategic planning of the institution and that represented on decision making bodies are more likely 
to have an impact. In particular for CETL that provide services at the central level and thus serve different disciplines and faculties it is important that they are able to develop a crossdisciplinary focus. CETL also work more effectively if they have a clear mission and teaching excellence is already important at the institution.

Hindrances to an effective functioning of CETL appear to be related to their implementation (Gosling \& Turner, 2014). For those CETL that are not aligned to existing cultures, practices and strategies or connected to the prior planning of the institution it is difficult to become accepted. This is also true for CETL that were not established in a consultation process between university leadership and staff. CETL that appear to not use their funding in an entrepreneurial way also do not gain legitimacy. CETL are also contested by staff if they lack clear goals or have a mission overload. Further, the support of the leadership has to be adequate, CETL that do not act autonomously of the institutional leadership are often perceived with suspicion. On the other hand, a lack of support from leadership makes it also difficult for CETL. CETL that do not have strong leadership themselves are also often contested. Finally, those CETL that cannot provide incentives or resources to promote activities improving the quality of teaching and learning also face difficulties.

\subsubsection{CETL as networks of teachers}

At some higher education institutions CETL have been established as networks among teachers. They often function as a project, thus they have less formalized structures. Also their scope is limited: their activity area is often limited to a department or faculty. These projects also have their own staff who coordinate or support the centre's activities. Responsibility and the major improvement activities, however, lie with the teachers who take different roles in the CETL, for example as leaders of work packages that are part of the project. Mostly these centres provide teachers with the opportunity and resources to develop and conduct their own (innovative) teaching project. These resources include time, i.e. teachers often receive an increase on the time they can spend for teaching. They thus have to spend less time on other duties. When doing their projects teachers, however, have to use a 'scholarship of teaching approach', i.e. projects should be developed based on scientific evidence, an evaluation of the project should be done and results should be 
published. Within the project or centre a regular exchange between teachers is facilitated by the centre's staff. These CETL also actively share project results within their host institution or with a wider audience through a variety of different media such as publications, websites and presentations.

This type of CETL resembles to some extent the so-called Faculty Learning Communities (FLC). At US higher education institutions FLC are often initiated by Centres for Teaching and Learning that are located at the central institutional level (Beach \& Cox, 2009; Cox, 2004). These centres provide resources for the FLC such as facilitating group meetings or material to inform the group members. Mostly FLC consist of 8 to 12 teachers who meet on a regular basis for a certain period to discuss issues around teaching and learning. FLC are composed quite differently: some FLC consist of teachers from the same entrance cohort (e.g. junior faculty) other FLC concentrate on one topic. Teachers participate in a FLC on a voluntary basis while the groups are lead and supported by staff from the centre. Groups also build their own curricula. The group leaders support the teachers in dealing with the topic in a scientific or methodological manner, i.e. they promote scholarship of teaching and learning. Thus group leader provide the members of their groups with background knowledge on student learning, teaching and learning formats as well as on student assessment. Teachers participating in those groups often develop and run teaching projects. Beside academic consultation the groups provide the opportunity to reflect the projects and discuss outcomes. Studies run by Centres for Teaching and Learning that engage in FLC revealed that teachers who were taking part in a FLC changed their teaching practices. Also for students a change in learning outcomes was stated. Within the groups a shared understanding and values of high quality teaching developed. Nonetheless, as the curricula of the group is developed in a democratic process it might not meet the demands of all group members. Those teachers were less motivated to engage in the group activities as these are require resources such as time and the willingness to learn about new subjects. FLC, however, also attract a certain type of academic staff. Mostly teachers who have a strong interest in teaching already engage in these groups (Beach \& Cox, 2009; Cox, 2004). 
Studies on FLC also state that they are effective in changing teaching practices as well as in generating better learning outcomes for students. As these results are based on surveys among students and teachers facilitating or hindering factors are mostly found at the individual level. In particular teachers' and students' attitudes towards teaching and learning were found to facilitate a stronger engagement and to change teaching practices significantly. The institutional context and the way FLC engage teachers has not been researched in these studies. According to survey results the institutional context, however, did not seem to matter as similar changes in teaching and learning practices occurred across the surveyed institutions (Beach \& Cox, 2009, p. 25).

\section{Two CETL compared ${ }^{1}$}

The literature thus indicates some factors that have an impact on how well CETL can facilitate activities aiming to improve of the quality of teaching and learning. In the following two institutions that implemented CETL will be studied in more detail. The first case is a German research university that has implemented a CETL as a department. The second case refers to a mono-disciplinary higher education institution in Norway that has implemented a CETL as a network of teachers.

\subsection{Germany}

The first centre is located at a German research university. The institution is rather large with more than 40,000 students and 5,000 staff members. The university is a comprehensive university. Due to its location and historical roots the university attracts students from diverse socio-economic and ethnic backgrounds, i.e. it the student population has a high percentage of students with a migration background and firstgeneration students. At this institution the CETL (in the following: the Centre) has been

\footnotetext{
${ }^{1}$ The two cases have been studied for the project CETLFUNK. In this ongoing project in total eight CETL in Germany, England, Norway and the Netherlands are researched with intensive case studies. The project seeks to understand how CETL support the university leadership when steering teaching and the CETL role in the discourse around teaching and learning. The project is funded by the German Federal Ministry of Education and Research (01PB14009 - CETLFUNK).
} 
established in the mid of the 2000. Currently it is a service unit that is located at the central university level. Its status, however, has changed in the recent years. The Centre is a followup unit of a former so-called higher education didactics centre which major task was academic development. Currently the Centre provides services in four major areas: didactical training for academic staff, professional development of early career researchers, development and implementation of a quality management system, in particular the implementation of a self-accreditation system, and as a cross-sectional task: the promotion of gender- and diversity management throughout the university. The Centre reports to the Vice-Rector for Teaching and Learning and engages in supporting the university leadership in developing strategies, foremost in the area of teaching and learning and gender and diversity.

The Centre also coordinates a university-wide project funded by the German funding scheme 'Quality of Pact for Teaching' (Qualitätspakt Lehre). This project consists of a number of sub-projects which aim to improve teaching and learning by either testing/experimenting with innovative teaching formats or providing preparatory classes for first year/first generation courses. These sub-projects are located at various levels at the university, e.g. at faculty level or at other service units. The majority of the Centre's staff are educational specialists that provide services in the different activity areas mentioned. They do not have other academic roles at the university or teach in the programmes. With regard to the university-wide project funded by the Quality Pact, a number of staff work to run these project. Academic staff are 'clients' to the Centre. They can enrol in the Centre's courses and projects, which are considered as professional development activities. The Centre also offers individualized didactical trainings such as coaching of professors or other senior academic staff. It also supports teachers who would like to develop innovative teaching projects. Those teachers are supported by informing them about potential funding possibilities and helping them to write the bid for the project. The Centre delivers input to the project by pointing teachers to research literature and evidence available for similar teaching projects. Didactical courses are mostly offered for staff from all faculties, i.e. there are no discipline specific courses. The majority of course participants are early career researchers, senior academic staff attend the Centre's courses less frequently. New 
academic staff is informed about the Centre when they start to work about the university. The Centre, however, does not reach out to academic staff by advertising its services to the academic staff on a regular basis. Staff interested in academic development, improving teaching and learning activities have to make contact with the Centre themselves and ask for support. The Centre thus resembles the type 'organisational unit' as has been described in the foregoing section.

\subsubsection{Teaching and Learning Micro Cultures}

To learn about the institutional teaching culture, teacher interviewees were asked for their personal view on what quality teaching means to them and what kind of values they prefer when teaching. These questions were also raised in the interviews with Centre's staff and the university leadership. The analysis focused on to what extent interviewees argue in similar ways and in what context they developed their perspective.

For this case we found some common ground when defining what good teaching is. The majority of teachers interviewed stated that good teaching should engage and motivate students as well as to provide them with sufficient (theoretical) knowledge that is useful in their later professional life. Though converging for these aspects, teachers have strong individual ideas of what good teaching or quality in teaching is. Most of them developed these ideas throughout their own biography rather than when engaging with their colleagues or within the institution. Teaching is also regarded as an individual responsibility, i.e. problems in teaching were perceived as personal failures, acquiring teaching competences is perceived as an individual journey that is fuelled by a natural talent for teaching. Respondents also state very different challenges teaching and learning in higher education has to address. These challenges are often related to the context and problems respondents face in their everyday routines. The university's teaching and learning strategy has only little importance in the teachers' perception of teaching and learning. The majority of them is not aware of the strategy or perceive it as having only little relevance for their teaching activities. Some of the teachers state that they agree with the values and goals mentioned in the strategy, but they do not feel well prepared to deal 
with them or to apply them in their teaching. Also a lack of resources to develop those competences is mentioned.

Teaching is also perceived as a strongly individualized task, i.e. preparing and running a course was frequently defined as a task for one person. When preparing a course most teachers did not have an elaborated didactical approach. Though the majority of teachers highly valued that their teaching should engage and motivate students, they hardly addressed the question how students learn and what teaching could effectuate this. Most of them, in particular those who did not participate in any didactical training, state that the engagement of student is mostly dependent on how well or interestingly they present the knowledge in the classroom. To them a good teacher is mostly a good presenter that is more knowledgeable in the field of study than the students. Those teachers also did not recognize that there is pedagogical or didactical knowledge that could help them to run a class or a course. They mostly argued that they need to have elaborated knowledge of their field of study to be a good teacher.

The majority of teachers gained their teaching knowledge practices through 'learning by doing'. When they started their teaching career they were mostly thrown into this activity without any (didactical) preparation. Often they did not have colleagues with whom they could talk about different methods to run or prepare a class, a course or an assessment. These teachers mostly developed their teaching practices based on their experiences throughout their own studies. Some of them also stated that they have developed these practices in trial and error processes. Only very few teachers stated that they use a scholarship approach to teaching and learning, i.e. formulating learning goals and competencies, informing themselves about good ways how to engage students in adequate learning processes, how to assess students and how to research how effectively the teaching was.

Further, teachers also state they hardly exchange with their colleagues about teaching practices. There is, however, a lot of talk about teaching at different levels. In regular meetings at faculty or chair level teaching issues are addressed. Mostly the discussion of teaching addresses organizational problems such as overlapping schedules, lack of 
resources, planning of the teaching programme for the upcoming semesters or complaints of students. Teaching practices are not addressed and the majority of teachers consider them to be private issues. There are, however, also self-organized or informal meetings among teachers at faculty or chair level were teaching practices are discussed. Mostly early career researcher who have a strong interest in developing their teaching competencies organise the meeting. Teachers participate in the meetings voluntary and frequently outside their paid working hours and they do not receive any resources or support.

Though there might be differences at faculty or department level one can assume that a strong individualized teaching micro culture is prevailing at this university. Though teachers strongly engage in good teaching the majority of them does perceive teaching as a collaborative activity. Also, there is only little awareness that there is pedagogical or didactical knowledge that could be helpful in preparing courses, classes and assessments. Thus, only few teachers were aware of the theoretical backgrounds of how students learn. To them motivating students to learn would be achieved by entertaining students or being a good presenter.

\subsubsection{The Centre's Engagement Strategy}

Centre staff mentioned that they do not have an overall engagement strategy. As stated above, the Centre does not contact academic staff on a regular basis to inform about its activities. Rather, those staff interested in academic development have to request its support. While early career researchers frequently do so, the centre mentions that it is difficult to reach out for more senior academic staff. Senior staff that request support are provided with individual coaching. Centre staff and leadership that their promotion activities to engage teachers in quality teaching and learning do not have a strong impact and that have difficulties to promote a more collaborative teaching micro culture.

There are a number of factors that contributed to this situation. In particular Centre staff stated that there are different layers of knowledge at the university and that it is difficult to bridge between them. On the one hand there is the layer of teaching knowledge that is presented by the Centre staff. This explicit knowledge is based on a more methodological 
approach on teaching and learning and includes for example basic didactical knowledge, learning theories and evidence on effective teaching methods. It thus represent a discipline of its own. On the other hand there is the layer of teaching knowledge as presented by the academic staff. This implicit knowledge is mostly based on the personal experiences of the teachers. It has very often been developed in a trial-and-error process, it also represents practices teachers have been experiencing themselves as students. This knowledge has been reflected also, but mostly in an individual manner rather than in a collaborative setting. Teachers themselves frequently do not relate their teaching competencies to this knowledge. To them being an expert in their field of study is much more important for good teaching. Bridging between these two knowledge layers is difficult in particular because the explicit knowledge base of teaching has already established an elaborated language, but there is hardly a language to express the implicit knowledge of the teachers. This makes it difficult for the teachers to communicate about teaching, to identify potential problems they might experiences in the class-room as well as to understand the educational professionals. Some teachers argued that they experience exchanges with the educational specialist as a threat because they perceive their support as a strong intervention in academic freedom. One teacher respondent stated that this perception is also motivated by a certain fear among teaching staff. Reflecting their own teaching practices and learning about alternative approaches would question their efforts and investment in establishing their teaching practices so far.

Another important factor is strongly related to the academic career system. Moving up the career ladder and in particular passing the bottleneck to move to a permanent position requires academic staff to strongly invest in their research performance. Investments in teaching performance are less important to academic staff as these do not have a strong impact on upward career mobility. Against this background, investments in teaching competencies appear to be ill-motivated.

The way the Centre promotes activities to improve the quality of teaching and learning often takes a strong individualized perspective. Training, coaching and supporting the implementation/development of innovative teaching projects is related to developing or 
professionalizing individual academics rather than engaging groups of teachers. There is also a strong idea that the Centre should provide academics with knowledge by transmission. Reflecting teachers' tacit knowledge about teaching practices as well as developing shared values of high quality teaching and learning through collaboration of teachers does not play an important role in the Centre's activities.

Another, but less strong factor is related to the lack of preparation of academic staff for teaching activities. The majority of teachers believes that teaching requires excellent expertise in their field of study. For the design of teaching and learning processes, however, they consider their experience and intuitive knowledge as sufficient. This focus prevents teachers from reflecting teaching and learning processes from a research perspective that would allow to identify effective methods and practices.

Finally, also the absence of formal time regimes hinder teachers to engage intensively in teaching practices or in developing (innovative) teaching projects. A major problem here is that employment contracts do not define percentages of working time that have to be spent on research and teaching tasks. Though contracts include the number of week hours for teaching, they do not state how much time in total has to be spend on teaching (including preparation, etc.). This makes it difficult to provide teachers with resources, such as time, for the development of teaching projects, or to give them an incentive to pursue further training to improve their teaching.

\subsection{Norway}

The case represents a higher music education institution that has established a Centre for Excellence in Education (in the following CEE) in 2014. The institution is rather small, it has around 600 students following bachelor, master and doctoral training in instrumental teaching but also in related subjects such as music pedagogy or music theory. It also has about 400 academic staff with a high percentage of part-time instrumental teachers. The institution is highly selective, i.e. students have to pass a thorough selection procedure to get accepted. The CEE receives funding from the Norwegian SFU scheme. The CEE has three major objectives with regard to improving teaching and learning: Advancing music 
performance teaching, enhancing the quality of student's instrumental practice, in particular by cross-genre training, and to better prepare students for their later careers in the globalized music society (CEE application, p. 1).

The CEE is organized similar to the Faculty Learning Committee model presented in the foregoing section. Thus, academic staff take roles and responsibilities in the project, staff involved in the project meet regularly to exchange about their work and experiences. The project is structured along the three major goals, i.e. for each goal work packages have been implemented that cover different aspects. The subprojects offer academic staff the opportunity to run their own small educational project for a limited period (e.g. for a semester). These projects are developed by the teachers themselves. To conduct the project teachers have to apply to the CEE. Selected project receive resources (in particular time) and support from the CEE. Teachers who run small educational projects meet regularly during semester and exchange their experiences. There is also an open-door policy, teachers are invited to attend the teaching of their peers. Teachers are also asked to document the outcomes of their projects; also here they receive support from the project leaders. Project outcomes feed into publications that are spread widely in the institution but also shared with other music education institutions and on the CEE's website. Project outcomes are also presented on a so-called 'Education Day' of the institution as well as on national and international conferences.

\subsubsection{Teaching and Learning Micro Cultures}

For this institution we found a very high congruency of teacher answers when asking for their personal view on good teaching and what are important values in teaching. With regard to good teaching the majority of respondents highlighted three major aspects. First good teaching should help the students to develop an ownership of or responsibility for their own learning. Second, good teaching helps students to define their own goals and to select where they would like to develop as musicians. Third, good teaching prepares students to be able to manage their own careers, i.e. to develop entrepreneurial competences to face the challenges of the changing music society. Shared values for good teaching are the respect for the student, her or his knowledge and competences. The 
relationship between teacher and student should be trustful and should leave the student room to develop. Further, being open for collaboration and sharing with peer teachers is found a very important competence for teachers. Interestingly, there was also a strong consensus in what is perceived as challenge to teaching. Here the majority of teachers stated that the student population has become diverse in the sense that they have nowadays more diverse goals concerning the direction they would like to develop as a musician. They also state that students' attitude has changed: students have become more self-confident and want to develop more freely. Also, the increasing competition on a more globalized music market is widely defined as a challenge that requires higher education institutions to better prepare their students for later careers. Also, overcoming the strong privacy prevailing in music education (one-on-one teaching; master-apprentice relationship) is identified as a challenge.

There was only very low variation with regard to their perception of teaching across the different groups that were interviewed. The majority of the respondents referred to the aspects mentioned in a similar manner, some of them even used similar words when describing their personal view on teaching. There were also hardly differences between teachers, managers/administrative personal and the institutional leadership. Even persons who did not yet participate in the CEE's activities stated different perceptions.

Looking at the content of the definitions reveals that these reflect an elaborated approach to teaching and learning. A student-oriented as well as a learning-oriented focus is strongly applied, and teaching is seen in a broader context, i.e. respondents are aware of the goals of teaching and the several purposes it should serve. The institution as well as the CEE thus were quite successful in developing a common sense about teaching and learning. Most teachers also stated that they developed their teaching practices in the context of the institution. Instrumental teachers however stated their own experiences of being taught as a student had a strong influence on their ideas about teaching, but they were also aware of pedagogical and didactical knowledge that helps them to reflect and further develop their teaching practices. 


\subsubsection{The CEE's engagement strategy}

CEE staff and leaders mention that when developing the Centre plan they were aware of the need to also develop an idea how to engage teachers in its activities. They also were aware that they need to promote central ideas and values underlying the work of the CEE.

The already existing institutional culture had a strong impact in this respect as it helped the CEE to bridge between knowledge presented by the CEE and the tacit knowledge of teachers. Unlike other music academies the institution was already engaging in evidence based educational development and also in research on music education or other music theory for a number of years. This provided the institution with expertise on educational development on the one hand. On the other hand interviewees also stated already knew how to carefully facilitate communication instrument teachers and education developers. Also the composition of institutional leadership was accounting for this: the team of leaders was always composed of staff from both the more educational-theoretical and the more practical departments. Institutional leadership also paid high attention to bottom-up management. The leadership strongly promoted ongoing exchange and communication across the different groups.

The definitions of good teaching and learning and the preferred values for teaching and learning further strongly reflect the institution's strategy with regard to teaching and learning. This strategy was had been elaborated in a yearlong bottom-up process involving the different internal stakeholders of the institution (staff, students, leadership). The strategy was written by a number of working groups, but there was also a steering group consisting of staff and students who worked together with an external consultant. Different versions of the strategy were discussed in meetings that were open to all staff and students. These meetings were attended by a quite high number of persons, and their feedback was integrated in the text. The strategy states clearly formulated development goals for a period of 10 years. However, the strategy also establishes mid-term reviews to evaluate achievements and adjust goals. The majority of respondents stated that the strategy had relevance for their daily teaching as they would share the values included in the strategy, in particular the importance of collaboration and sharing among teachers in the institution 
but also outside the institution. For the CEE too, clear objectives were formulated, which were known by all interviewees and were also supported by them. Most respondents found these goals relevant to their daily practice and also could see the benefits of the different projects run in the CEE. The university leadership also states that there is a strong alignment between the strategy and the CEE activities. CEE activities intend to support the implementation of the strategy. This is done by for example by testing different models of innovative teaching in order to promote more student-centred education activities.

The high degree of shared values and perceptions of teaching is also related to the fact that all teachers at the institution are obliged to attend a preparatory didactical course for their teaching activities. Most teachers state that this course helped them to reflect their teaching activities/practice in a more reflected manner. Those persons who were involved in establishing the course find that the high acceptance of the teacher training was mainly related to the fact that the content has relevance for the music teachers as it clearly connects the educational knowledge to their practical work. Another success factor was that the course put high importance on the stimulating discussions and group work among teachers, also stimulating them to engage in small projects.

The principle to align the educational development as close as possible with the daily practice of the teachers is also used in the projects that are run under CEE's realm. Teachers who would like to participate in the projects can freely develop their own project idea. Their autonomy and competence is fully respected also by the CEE. To realize their project they receive support from the project leaders and their peers in the project. The CEE also provides them with financial and other resources to run the project. To develop and run their project the teachers also receive working time, i.e. part-time teachers receive an increase of their contract in terms of hours. For full-time teachers the percentages they have to spend on teaching or development work are changed, mostly their teaching load becomes decreased.

Dissemination of results in the institution itself as well as with national and international audiences is a main task of the CEE. A number of different channels to disseminated results have been established such publications, a website and participation in (inter)national 
conferences. Besides publishing results of the CEE project there was also a high effort to make the CEE as such, i.e. its goals and activities well known among all staff and students. (Compulsory) staff days were dedicated to informing about the CEE activities only. Also the selection of project leaders for the different work packages was done carefully. Mostly heads of departments were selected as work package or project leaders who informed their colleagues about the CEE in regular department meetings. Teachers who took part in the first round of projects were also chosen according to how well they were connected to the other teachers. This should promote internal communication about the CEE. In order to open or broaden existing communication structures, project groups had teachers with diverse backgrounds (for example they were coming from different departments). This facilitated that teachers were forced to talk to colleagues they hardly met in the past. The regular meetings of the project groups serve to stimulate the reflection of the teachers on the projects carried out, but above all also to encourage them to express their tacit knowledge. They are also asked to report on the project outcomes. Here they receive support from the project leader. The reports feed into printed publications that are distributed to each teacher in the institution. Dissemination however also benefitted from the existing vivid communication culture in the institution. Here, the interviewees pointed out that the institution has set up a wide range of committees, which involve teachers in various ways and give the opportunity to participate.

\section{Conclusions: effective engagement strategies}

Research so far stated that promoting activities to improve teaching and learning are difficult to implement at higher education institutions. This was in particular true for CETL as they frequently face difficulties to gain acceptance and legitimacy among academic staff for the kind of knowledge they provide with their promotion activities. Recent research on HEFCE CETL stated the lack of an adequate engagement strategy made it difficult for them to effectively promote their activities (Saunders et al., 2008). This research however did not address the various ways CETLs are implemented at higher education institutions. Other research investigated to what extent teacher who participated in CETL activities 
changed their teaching practices. These studies revealed more positive results for the impact of CETL as those teachers frequently changed their teaching behaviour as well as student learning outcomes improved (Beach \& Cox, 2009; Bélanger et al., 2011). This research, however, used a strong individualistic perspective, finding individual attitudes and motives of teachers as most important factors for the success of improvement activities. Other research highlights the role of teaching and learning micro cultures for engaging teachers in high quality student oriented teaching. Here stimulating communication and exchange between teachers about teaching practices is found to be fundamental to developing such micro cultures (Mårtensson \& Roxå, 2016a; Mårtensson \& Roxå, 2016b). Strong micro cultures, i.e. cultures where teachers share values, beliefs and knowledge about teaching, are able to orient teaching practices, support the development of a teacher identity and to effect changes in teaching practices. This research however does not explicitly consider the role of CETL in stimulating and supporting these teacher networks, mostly networks that developed more naturally have been studied (e.g. (Mårtensson \& Roxå, 2016b).

Therefore in the foregoing sections the engagement strategies of two highly contrasting types of CETL were investigated. The analysis focused on the extent shared beliefs, values and knowledge with regard to teaching and learning have been established at the two institutions and how CETL support these processes with their engagement strategy. It also addressed facilitating and hindering factors for these engagement strategies. Though one has to consider that this working paper investigates only two highly contrasting cases a number of preliminary conclusion are drawn.

Comparing the two cases it appears that CETL that are able to bridge between explicit pedagogical knowledge and the tacit and implicit knowledge of teachers are more likely to successfully gain acceptance and legitimacy for this knowledge among academic staff. While the Norwegian institution had already established communication between education developers and teachers, this was still a difficult issue at the German institution. At the Norwegian institution the fact that teachers have to participate in didactical courses strongly supports the acceptance. Tailoring the courses to the everyday practices and 
routines of teachers is important here. This helped teachers to accept that the didactical knowledge helps them to do their teaching rather than assuming that the knowledge would replace their knowledge and teaching practices. Adapting to the teachers everyday routines and practices was rather difficult in the German institution. This is due to the central location of the CETL and its purpose to serve all faculties and discipline. This makes it difficult for Centre staff to adapt to already existing cultures at faculty or department level or to have regular contact with academic staff. Also, the approach that the Centre does not actively advertise its services to academic staff, rather that academics have to request support does not smoothen the communication between education developers and academic staff, as it establishes a slightly hierarchical relationship between the two groups.

Assigning the teachers an active role in and responsibility for improving activities taking place under the realm of the CETL also appears to stimulate a stronger engagement of teachers. Here the Norwegian case made clear that teachers very much enjoy the opportunity to develop their own teaching projects. Exchanging and collaborating with colleagues who work on similar tasks was reported as very helpful and inspiring. The fact that the CETL was able to provide appropriate resources, in particular time through the exemption from other activities, was considered a further important incentive. From the German case it became clear that only teachers who were strongly interested in teaching developing projects and who had found their own funding for that were engaging in these. For the majority of teachers the CETL was a service unit and they identified themselves as consumers of the services provided. Teachers thus had limited opportunities to develop their own projects and receive appropriate support. Also, stimulating networks and collaboration among teachers was not mentioned as an engagement activity by CETL staff. Networks among teachers to develop and discuss teaching practices were frequently initiated by the teachers themselves.

The scope and the size of the institution, however, also is an important factor. At the Norwegian institution the CETL was definitely more successful in developing a collaborative teaching culture simply because of the small institution size. This makes it much easier to promote the CETL, to select teachers who take responsibilities and roles in 
the CETL projects and to disseminate project results. The CETL, however, also reached out actively to the teachers. Defining the CETL as project that provides opportunities to develop and experiment in collaboration with others makes participation in its activities very attractive. At the German institution, the CETL as a central level service unit certainly is more distant to the teachers. Also providing services rather than opportunities to actively engage in developing own teaching projects does not stimulate collaboration among teachers. Considering a decentralized implementation of FLC at faculty level could help to more strongly engage teachers in enhancement activities. 


\section{References}

Beach, A. L., \& Cox, M. D. (2009). The Impact of Faculty Learning Communities on Teaching and Learning. Learning Communities Journal, 1(1), 7-27. Retrieved June 28, 2016.

Bélanger, C., Bélisle, M., \& Bernatchez, P.-A. (2011). A Study of the Impact of Services of a University Teaching Centre on Teaching Practice: Changes and Conditions. Journal on Centers for Teaching and Learning, 3, 131-165. Retrieved July 01, 2016.

Challis, D., Holt, D., \& Palmer, S. (2009). Teaching and learning centres: towards maturation. Higher Education Research \& Development, 28(4), 371-383.

Cox, M. D. (2004). Introduction to faculty learning communities. New Directions for Teaching and Learning, 2004(97), 5-23. Retrieved June 28, 2016, from https://cms.ysu.edu/sites/default/files/documents/Introduction_to_Faculty_Learning_Commun ities_by_Milt_Cox.pdf.

Gosling, D., \& Turner, R. (2014). Responding to contestation in teaching and learning projects in the Centres for Excellence in Teaching and Learning in the United Kingdom. Studies in Higher Education, 40(9), 1573-1587.

Kottmann, A., Huisman, J., Brockerhoff, L., Cremonini, L., \& Mampaey, J. (2016). How Can One Create a Culture for Quality Enhancement?: Final Report. Enschede, Ghent. Retrieved January 15, 2017.

Kottmann, A., \& Cremonini, L. (2017, in print). Midterm Report CETLFUNK. Enschede.

Lieberman, D. (2005). Beyond faculty development: How centers for teaching and learning can be laboratories for learning. New Directions for Teaching and Learning, 131, 87-98. Retrieved June 28, 2016.

Mårtensson, K., \& Roxå, T. (2016a). Peer engagement for teaching and learning: competence, autonomy and social solidarity in academic micro cultures. Uniped, 39(2), 131-143. Retrieved June 26, 2016, from https://www.idunn.no/file/pdf/66873000/peer_engagement_for_teaching_and_learning_compe tence_auto.pdf.

Mårtensson, K., \& Roxå, T. (2016b). Working with networks, micro cultures and communities. In D. Baume \& C. Popovic (Eds.), The staff and educational development series. Advancing practice in academic development (pp. 174-187). London: Routledge.

Raaheim, A. \& Karjalainen, A. (2012). Centres of excellence in university education, Finland 19992012: An evaluation, from KKA - The Finnish Higher Education Evaluation Council: .

Saunders, M., Machell, J., Williams, S., Allaway, D., Spencer, A., Ashwin, P., et al. (2008). 2005-2010 Centres of Excellence in Teaching and Learning programmes: Formative evaluation report to HEFCE by the Centre for Study in Education and Training/Institution of Educational Technology, from http://www.hefce.ac.uk/media/hefce/content/pubs/indirreports/2008/missing/20052010\%20CETL\%20programme\%20formative\%20evaluation.pdf. 
SQW (2011). Summative evaluation of the CETL programme: Final report by SQW to HEFCE and DEL. HEFCE, from

http://www.hefce.ac.uk/media/hefce/content/pubs/indirreports/2011/RE,1111,Eval,of,CETL/ rd11_11.pdf.

Webler, W.-D. (2012). Vergleich von Zentren für Hochschul- und Qualitätsentwicklung. Personalund Organisationsentwicklung, 7(4), 130-133.

Wenger, E., McDermott, R., \& Snyder, W. M. Cultivating Communities of Practice : A Guide to Managing Knowledge. Boston: Harvard Business School Press. 
The Center for Higher Education Policy Studies (CHEPS) is a research institute (WHW, Article 9.20) located in the Faculty of Behavioural and Management Sciences within the University of Twente, a public university established by the Dutch government in 1961. CHEPS is a specialized higher education policy centre that combines basic and applied research with education, training and consultancy activities.

Policy Studies 